\title{
Evidence That Calcium Release-activated Current Mediates the Biphasic Electrical Activity of Mouse Pancreatic $\beta$-Cells
}

\author{
D. Mears ${ }^{1,2}$, N. F. Sheppard, Jr. ${ }^{1}$, I. Atwater ${ }^{2}$, E. Rojas ${ }^{2}$, R. Bertram ${ }^{3}$, A. Sherman ${ }^{3}$ \\ ${ }^{1}$ Department of Biomedical Engineering, The Johns Hopkins University, Baltimore, MD 21218 \\ ${ }^{2}$ Laboratory of Cell Biology and Genetics NIDDK, National Institutes of Health, Bethesda, MD 20892 \\ ${ }^{3}$ Mathematical Research Branch, NIDDK, National Institutes of Health, Bethesda, MD 20892
}

Received: 5 June 1996/Revised: 15 August 1996

\begin{abstract}
The electrical response of pancreatic $\beta$-cells to step increases in glucose concentration is biphasic, consisting of a prolonged depolarization with action potentials (Phase 1) followed by membrane potential oscillations known as bursts. We have proposed that the Phase 1 response results from the combined depolarizing influences of potassium channel closure and an inward, nonselective cation current $\left(I_{\text {CRAN }}\right)$ that activates as intracellular calcium stores empty during exposure to basal glucose (Bertram et al., 1995). The stores refill during Phase 1 , deactivating $I_{\text {CRAN }}$ and allowing steady-state bursting to commence. We support this hypothesis with additional simulations and experimental results indicating that Phase 1 duration is sensitive to the filling state of intracellular calcium stores. First, the duration of the Phase 1 transient increases with duration of prior exposure to basal $(2.8 \mathrm{~mm})$ glucose, reflecting the increased time required to fill calcium stores that have been emptying for longer periods. Second, Phase 1 duration is reduced when islets are exposed to elevated $\mathrm{K}^{+}$to refill calcium stores in the presence of basal glucose. Third, when extracellular calcium is removed during the basal glucose exposure to reduce calcium influx into the stores, Phase 1 duration increases. Finally, no Phase 1 is observed following hyperpolarization of the $\beta$-cell membrane with diazoxide in the continued presence of $11 \mathrm{~mm}$ glucose, a condition in which intracellular calcium stores remain full. Application of carbachol to empty calcium stores during basal glucose exposure did not increase Phase 1 duration as the model predicts. Despite this discrepancy, the good agreement between most of the experimental results and the model predictions provides
\end{abstract}

Correspondence to: D. Mears evidence that a calcium release-activated current mediates the Phase 1 electrical response of the pancreatic $\beta$-cell.

Key words: Islet of Langerhans - Stimulus-secretion coupling - Endoplasmic reticulum - Acute insulin response - Mathematical model - Glucose

\section{Introduction}

\section{$\beta$-Cell Biphasic ResPonse}

Pancreatic $\beta$-cells in vivo (Porte \& Pupo, 1969) and in vitro (Curry, Bennett \& Grodsky, 1968; Lacy, Walker \& Fink, 1972) respond to step increases in extracellular glucose concentration with a biphasic pattern of insulin secretion, consisting of an initial rapid peak of insulin release (within about $5 \mathrm{~min}$ ) followed by a more slowly developing, sustained secretion (Ward et al., 1984; Grodsky, 1989). Non-insulin dependent diabetes mellitus (NIDDM) and several animal models of diabetes are characterized by loss of the rapid component of the response (Phase 1 or acute insulin response) during glucose tolerance tests (Cerasi, 1988). Furthermore, loss of the acute insulin response serves as a potent predictor for the development of insulin-dependent diabetes mellitus (IDDM) (Colman \& Eisenbarth, 1987). Therefore, elucidation of the cellular mechanisms underlying the biphasic response of the $\beta$-cell to glucose has important biophysical and clinical implications.

The electrical response of the $\beta$-cell to step increases in glucose concentration is also biphasic (Meissner \& Atwater, 1976), consisting of a prolonged depolarization (Phase 1) followed by steady-state oscillations known as 


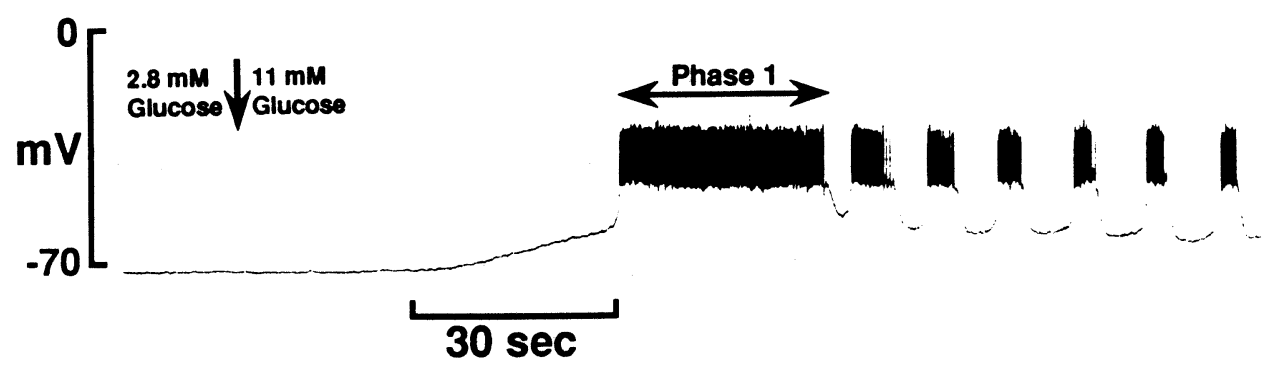

Fig. 1. Membrane potential from a $\beta$-cell in a mouse islet of Langerhans. The biphasic pattern of electrical activity following addition of 11 mM glucose (arrow) consists of a prolonged spiking period (Phase 1) followed by steady-state oscillations or bursts.

bursts (see Fig. 1). Most investigations of $\beta$-cell electrical activity have focused on steady-state bursting. However, the clear relationship between $\beta$-cell electrical activity and insulin release (Meissner \& Schmeltz, 1974; Scott, Atwater \& Rojas, 1981) and the importance of the biphasic secretory response for maintenance of glucose homeostasis motivate a more thorough investigation of the ionic mechanisms underlying the transient phase of glucose-induced electrical activity. Here we present experimental and theoretical evidence that a calcium release-activated current is involved in Phase 1.

\section{Calcium Release-Activated CurRents}

Depletion of inositol 1,4,5-triphosphate $\left(\mathrm{IP}_{3}\right)$-sensitive calcium stores results in activation of plasma membrane ion channels in a variety of nonexcitable cell types (reviewed in Putney \& Bird, 1993; Fasolato, Innocenti \& Pozzan, 1994). The current through these channels is carried predominantly by calcium (calcium release activated $\mathrm{Ca}^{2+}$ current, $I_{\text {CRAC }}$ ), and serves to refill the calcium stores (Hoth \& Penner, 1992). A depletionactivated inward current may also exist in the pancreatic $\beta$-cell. Both muscarinic agonists, which empty calcium stores by stimulating production of $\mathrm{IP}_{3}$, and thapsigargin, which empties calcium stores by inhibiting the sarcoendoplasmic reticulum calcium ATPase (SERCA) responsible for calcium uptake (Thastrup et al., 1989), depolarize the $\beta$-cell membrane in the presence of glucose (Worley et al., 1994a; Bertram et al., 1995). Thapsigargin also stimulates manganese influx in insulin-secreting cells (Bode \& Göke, 19984; Leech, Holtz \& Habener, 1994). More direct evidence was provided by Worley and coworkers (1994a), who showed that depletion of intracellular calcium stores by removal of extracellular calcium activates a voltage-independent current in mouse $\beta$-cells. The persistence of the current in the absence of calcium and the reversal potential between -20 and $0 \mathrm{mV}$ (Worley et al., 1994a,b) indicate that the depletion-activated current may result from activation of nonselective cation channels (calcium release activated nonselective cation current, $I_{\mathrm{CRAN}}$ ). The nature of the signal between calcium stores and $I_{\mathrm{CRAN}}$ channels has not been determined in the $\beta$-cell, but does not affect the results and conclusions of this study.

\section{$I_{\text {CRAN AND BIPHASIC ELECTRICAL ACTIVITY }}$}

Worley and colleagues (1994a) were the first to propose a role for $I_{\text {CRAN }}$ in Phase 1, based on voltage-dependent release of stored calcium at the start of the transient. Here we support a different mechanism based solely on filling of intracellular calcium stores, with no major role ascribed to calcium release during Phase 1 . This hypothesis was described in a recent theoretical study in which $I_{\text {CRAN }}$ was included in a mathematical model of $\beta$-cell electrical activity (Bertram et al., 1995). The model accounted for the effects of muscarinic agonists and thapsigargin on glucose-induced electrical activity and intracellular calcium concentration, suggesting a role for $I_{\text {CRAN }}$ in these responses. Furthermore, the model was the first of its kind to predict a biphasic electrical response to glucose. As discussed in detail below, the biphasic response of the model occurs because calcium stores emptying during exposure to basal glucose, and the resulting $I_{\mathrm{CRAN}}$, while insufficient to affect membrane potential in basal glucose, keeps the membrane depolarized upon re-addition of stimulatory glucose until the calcium stores have refilled. In this paper, we present additional simulations using the model of Bertram et al. (1995) as well as supporting experimental evidence demonstrating that Phase 1 electrical activity is sensitive to the filling state of intracellular calcium stores. A portion of this work has been presented in abstract form (Mears et al., 1996).

\section{Materials and Methods}

\section{Membrane Potential Recordings}

Membrane potential was recorded from $\beta$-cells within mouse islets of Langerhans using intracellular microelectrodes as described previously (Atwater, Ribalet \& Rojas, 1978). Briefly, intact islets of Langerhans 
were dissected from the pancreas of 2-5 month old female mice and mounted into a sample chamber where they were perifused with Krebs solution containing (in mM): $120 \mathrm{NaCl}, 25 \mathrm{NaHCO}_{3}, 5 \mathrm{KCl}, 2.6 \mathrm{CaCl}_{2}$, $1.1 \mathrm{MgCl}_{2}$. The solution was equilibrated with $0_{2}: \mathrm{CO}_{2}(95 \%: 5 \%)$ to maintain the $\mathrm{pH}$ between 7.4 and 7.5 at $37^{\circ} \mathrm{C}$. Changes to the medium were made without adjusting for osmolarity. When calcium was removed from the solution, the $\mathrm{MgCl}_{2}$ concentration was increased to 10 $\mathrm{mm}$ to help maintain the impalement.

Microelectrodes were formed from borosilicate capillary glass having $2 \mathrm{~mm}$ external diameter, $0.7 \mathrm{~mm}$ internal diameter (FHC, Brunswick, ME) on a vertical puller (Narashige, Tokyo, Japan). The electrodes were filled with a $1: 1$ mixture of $1 \mathrm{M} \mathrm{KCl}$ and $1 \mathrm{M} \mathrm{K}$-citrate and had resistance $c a .150 \mathrm{M} \Omega$. Cells in the islet were impaled using an amplifier equipped with a positive feedback "cell puncture circuit,", and $\beta$-cells were identified based on bursting electrical activity in the presence of $11 \mathrm{~mm}$ glucose.

Phase 1 was defined throughout this study as starting when the membrane potential reached the depolarized plateau level $(\sim 45 \mathrm{mV}$ in Fig. 1) and ending when the membrane potential fell to $4 \mathrm{mV}$ below the plateau. The results and conclusions of the study are unaffected if different (but consistent) definitions of Phase 1 are used. Significance levels of the observed differences in Phase 1 duration were determined using the student's $t$-test.

\section{Mathematical Model}

The mathematical model used to simulate $\beta$-cell electrical responses for conditions corresponding to the experiments is essentially the same as that employed in Bertram et al. (1995), with minor changes as indicated below and in the Appendix. The model has a HodgkinHuxley-like formulation, with voltage $(V)$ determined by six ionic currents: two fast-activating $\mathrm{Ca}^{2+}$ currents, one noninactivating $\left(I_{\mathrm{Caf}}\right)$ and the other slowly inactivating $\left(I_{\mathrm{Cas}}\right)$; a delayed rectifying $\mathrm{K}^{+}$current $\left(I_{\mathrm{Kdr}}\right)$; a $\mathrm{Ca}^{2+}$-activated $\mathrm{K}^{+}$current $\left(I_{\mathrm{K}(\mathrm{Ca})}\right)$; an ATP-regulated $\mathrm{K}^{+}$current $\left(I_{\mathrm{K}(\mathrm{ATP})}\right)$; and a nonselective $\mathrm{Ca}^{2+}$ release-activated current $\left(I_{\text {CRAN }}\right)$. The latter current behaves like $I_{\text {CRAC }}$ in Bertram et al. (1995). Mass balance equations for the concentration of cytosolic free $\mathrm{Ca}^{2+}$ $\left(\mathrm{Ca}_{i}\right)$ and ER free $\mathrm{Ca}^{2+}\left(\mathrm{Ca}_{e r}\right)$ are also included, yielding:

$$
\begin{gathered}
C_{m} \frac{d V}{d t}=-\left[I_{\mathrm{Caf}}+I_{\mathrm{Cas}}+I_{\mathrm{Kdr}}+I_{K(\mathrm{Ca})}+I_{\mathrm{K}(\mathrm{ATP})}+I_{C R A N}\right] \\
\frac{d n}{d t}=\frac{\left(n_{\infty}(V)-n\right)}{\tau_{n}(V)} \\
\frac{d j}{d t}=\frac{\left(j_{\infty}(V)-j\right)}{\tau_{j}(V)} \\
\frac{d \mathrm{Ca}_{i}}{d t}=\frac{1}{\lambda}\left[\left(\frac{P_{\mathrm{leak}}}{P_{\mathrm{ip} 3}}+O_{\infty}\right)\left(\mathrm{Ca}_{e r}-\mathrm{Ca}_{i}\right)-\frac{J_{\mathrm{er}, \mathrm{p}}}{P_{\mathrm{ip} 3}}\right]+\frac{J_{\mathrm{mem}}}{V_{\mathrm{i}, \mathrm{eff}}} \\
\frac{d \mathrm{Ca}_{e r}}{d t}=-\frac{1}{\sigma \lambda}\left[\left(\frac{P_{\text {leak }}}{P_{\mathrm{ip} 3}}+O_{\infty}\right)\left(\mathrm{Ca}_{e r}-\mathrm{Ca}_{i}\right)-\frac{J_{\mathrm{er}, \mathrm{p}}}{P_{\mathrm{ip} 3}}\right]
\end{gathered}
$$

$C_{m}$ is the membrane capacitance, $n$ is activation of $I_{\mathrm{Kdr}}$, and $j$ is the slow inactivation of $I_{\text {Cas }}$. Expressions for the ionic currents are:

$$
\begin{aligned}
& I_{\mathrm{Caf}}=\bar{g}_{\mathrm{Caf}} m_{f, \infty}(V)\left(V-V_{\mathrm{Ca}}\right) \\
& I_{\mathrm{Cas}}=\bar{g}_{\mathrm{Cas}} j m_{s, \infty}(V)\left(V-V_{\mathrm{Ca}}\right) \\
& I_{\mathrm{Kdr}}=\bar{g}_{\mathrm{Kdr}} n\left(V-V_{K}\right)
\end{aligned}
$$

$$
\begin{aligned}
I_{\mathrm{K}(\mathrm{Ca})} & =\bar{g}_{\mathrm{K}(\mathrm{Ca})} \frac{\mathrm{Ca}_{i}^{5}}{\mathrm{Ca}_{i}^{5}+(0.55)^{5}}\left(V-V_{K}\right) \\
I_{\mathrm{K}(\mathrm{ATP})} & =\bar{g}_{\mathrm{K}(\mathrm{ATP})}\left(V-V_{\mathrm{K}}\right) \\
I_{\mathrm{CRAN}} & =\bar{g}_{\mathrm{CRAN}} r_{\infty}\left(\mathrm{Ca}_{e r}\right)\left(V-V_{\mathrm{CRAN}}\right)
\end{aligned}
$$

The $\mathrm{Ca}^{2+}$ currents as well as $I_{\mathrm{K}(\mathrm{Ca})}$ and $I_{\mathrm{CRAN}}$ are assumed to activate instantaneously. Values of all parameters and expressions for the functions $n_{\infty}(V), \tau_{n}(V), j_{\infty}(V)$ and $\tau_{j}(V)$ are given in the Appendix and figure captions.

Glucose regulation of electrical activity is through $I_{\mathrm{K}(\mathrm{ATP})}$. Addition of glucose is simulated by reducing the conductance $\bar{g}_{\mathrm{K} \text { (ATP). }}$. In this model, glucose-induced bursting is driven by the slow, voltagedependent oscillation of the $I_{\text {Cas }}$ inactivation variable, $j$. In the presence of an $\mathrm{IP}_{3}$-generating muscarinic agonist, this is superseded by high-frequency bursting driven by rapid oscillations in $\mathrm{Ca}_{i}$ acting through $I_{\mathrm{K}(\mathrm{Ca})}$. This interaction leads to muscarinic-like bursting only if the depolarizing current $I_{\mathrm{CRAN}}$ is present (Bertram et al., 1995).

The cytosolic and ER calcium concentrations (Eqs. 4 and 5) are determined by the calcium fluxes across the plasma and ER membranes, based on the analysis of $\mathrm{Li}$ and Rinzel (1994). The $\mathrm{Ca}^{2+}$ flux across the plasma membrane, $J_{\text {mem }}$, is denoted

$$
J_{\text {mem }}=-\alpha\left(I_{\text {Caf }}+I_{\text {Cas }}\right)-v_{\text {mem,p }} \frac{\mathrm{Ca}_{i}^{2}}{\mathrm{Ca}_{i}^{2}+k_{\text {mem,p }}^{2}}
$$

The first term accounts for $\mathrm{Ca}^{2+}$ influx through voltage-gated $\mathrm{Ca}^{2+}$ channels, and the second term, which has been modified from Bertram et al. (1995), accounts for efflux through plasma membrane pumps.

The $\mathrm{Ca}^{2+}$ flux across the ER membrane has three components:

$$
J_{\mathrm{er}}=\left(P_{\text {leak }}+P_{\mathrm{ip} 3} O_{\infty}\right)\left(\mathrm{Ca}_{e r}-\mathrm{Ca}_{i}\right)-J_{\mathrm{er}, \mathrm{p}}
$$

$P_{\text {leak }}$ is the $\mathrm{Ca}^{2+}$ leak permeability out of the ER; $P_{\mathrm{ip} 3}$ is the permeability through open $\mathrm{IP}_{3}$-activated channels; and $J_{\text {er,p }}$ is the flux into the ER through SERCA pumps. In the absence of muscarinic agonists, $P_{\mathrm{ip} 3}=0$ (see Appendix). Other parameters in the mass balance Eqs. (4) and (5) include the "effective volume" of the cytosolic compartment $\left(V_{\mathrm{i}, \text { eff }}\right)$, defined as the actual volume divided by the ratio of free to total $\mathrm{Ca}^{2+}$ in this compartment; the time scale parameter $\lambda=V_{\mathrm{i}, \mathrm{eff}}$ l $P_{\text {ip3 } 3}$, and $\sigma=V_{\text {er,eff }} / V_{\mathrm{i}, \text { eff }}$, the ratio of effective volumes of the cytosolic and ER compartments.

All other details of the model can be found in the Appendix and in Bertram et al. (1995). The model equations were solved numerically with a Gear method implemented in the software package LSODE.

\section{Results}

\section{Model EXHIBITS BiPHASIC ElECTRICAL Response to SteP INCREASE IN GluCOSE LEVEL}

Figure 2 shows the response of the model to simulated step changes in glucose concentration. In the presence of high (11 mM) glucose at steady-state, the model produces bursts of electrical activity and periodic intracellular calcium accumulations (Fig. $2 A$ and $B$, left side), as observed experimentally (Santos et al., 1991). The ER calcium concentration, and hence $I_{\text {CRAN }}$, changed little during each burst (Fig. $2 C$ and $D$ ). Reduction of glucose 

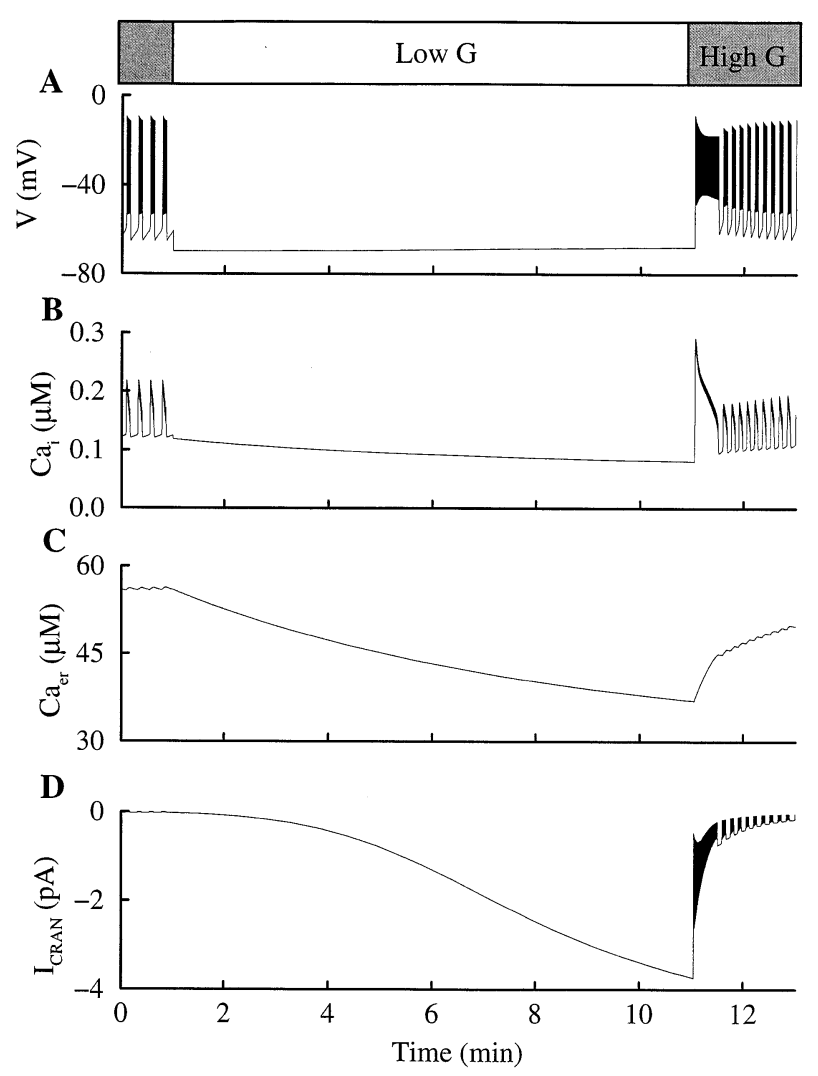

Fig. 2. Mechanism of biphasic response. Simulation result showing changes in $(A)$ membrane potential, $(B)$ intracellular calcium, $(C)$ endoplasmic reticular calcium, and $(D) I_{\text {CRAN }}$ in response to step changes in glucose concentration. Lowering of glucose concentration was simulated by increasing $\bar{g}_{\mathrm{K}(\mathrm{ATP})}$ from $150 \mathrm{pS}$ to $2000 \mathrm{pS}$. Return of stimulatory glucose was simulated by lowering $\bar{g}_{\text {K(ATP) }}$ to $150 \mathrm{pS}$. Phase 1 results from activation of $I_{\text {CRAN }}$ during the period in basal glucose, which keeps the membrane depolarized for a prolonged period upon re-addition of the sugar.

concentration, simulated as a step increase in the potassium conductance $\bar{g}_{\mathrm{K}(\mathrm{ATP})}$, caused the membrane to hyperpolarize and the intracellular calcium level to decrease (Fig. $2 A$ and $B$ ). The resulting decreased influx of calcium into the ER caused gradual depletion of calcium from the store and activation of $I_{\text {CRAN }}$ (Fig. $2 C$ and $D$ ). Activation of this depolarizing current had no effect on membrane potential in nonstimulatory glucose, because open $\mathrm{K}_{\mathrm{ATP}}$ channels keep the membrane near the potassium reversal potential under these conditions. A subsequent addition of glucose, simulated by decreasing $\bar{g}_{\mathrm{K}(\mathrm{ATP})}$, caused the cell to depolarize and fire action potentials, resulting in a rapid increase in intracellular calcium concentration. Since the ER was initially depleted, the depolarizing, excess $I_{\text {CRAN }}$ kept the cell depolarized and spiking for a prolonged period (Phase 1). Not until the ER refilled enough to almost completely deactivate $I_{\text {CRAN }}$ did the steady-state burst pattern ap-

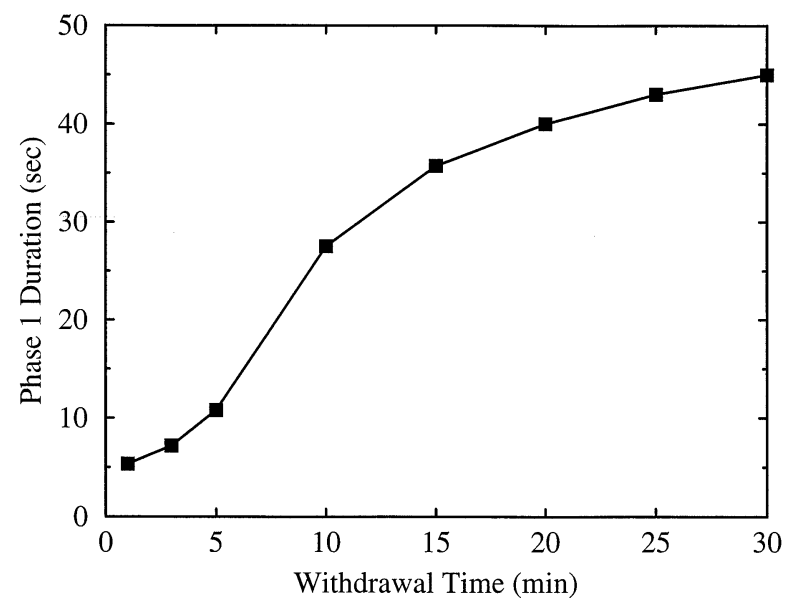

Fig. 3. Simulated Phase 1 duration versus glucose withdrawal time. The model predicts that Phase 1 duration increases with time of exposure to basal glucose.

pear. Note that less than $4 \mathrm{pA}$ of $I_{\mathrm{CRAN}}$, on top of the $100 \mathrm{pA}$ of total inward current carried by $I_{\text {Caf }}$ and $I_{\text {Cas }}$, makes the difference between Phase 1 and steady-state bursting. This is delicate but comparable to the variation in $I_{\mathrm{K}(\mathrm{ATP})}$ predicted by this and other models to mediate the transition from bursting to continuous spiking as glucose concentration is increased. Thus the model proposes that the Phase 1 electrical response to a step increase in glucose concentration occurs because $I_{\text {CRAN }}$ activates during the period in basal glucose, and does not inactivate until calcium stores have refilled. According to this hypothesis, the duration of Phase 1 is directly related to the time required for calcium stores to refill upon addition of stimulatory glucose. This prediction forms the basis for the theoretical and experimental results that follow.

\section{Phase 1 Duration Vs. Glucose Removal Time}

As shown in Fig. 3, the model predicts that Phase 1 duration increases with the amount of time that the cell is exposed to basal glucose (withdrawal time). This is because the ER drains slowly in the absence of stimulatory glucose (Fig. 2C), so the longer the cell is exposed to low glucose, the more depleted the store becomes, and more time is required for it to refill when stimulatory glucose is reapplied.

Figure 4 shows segments of a continuous membrane potential recording from a $\beta$-cell, illustrating variation in Phase 1 duration with glucose withdrawal time. Stimulatory (11 mM) glucose was applied (arrow in each trace) after the islet was exposed to basal glucose for the amount of time indicated at the start of each trace. The Phase 1 durations following exposure to basal glucose for $10 \mathrm{~min}$ (upper trace) and $20 \mathrm{~min}$ (middle trace) were 


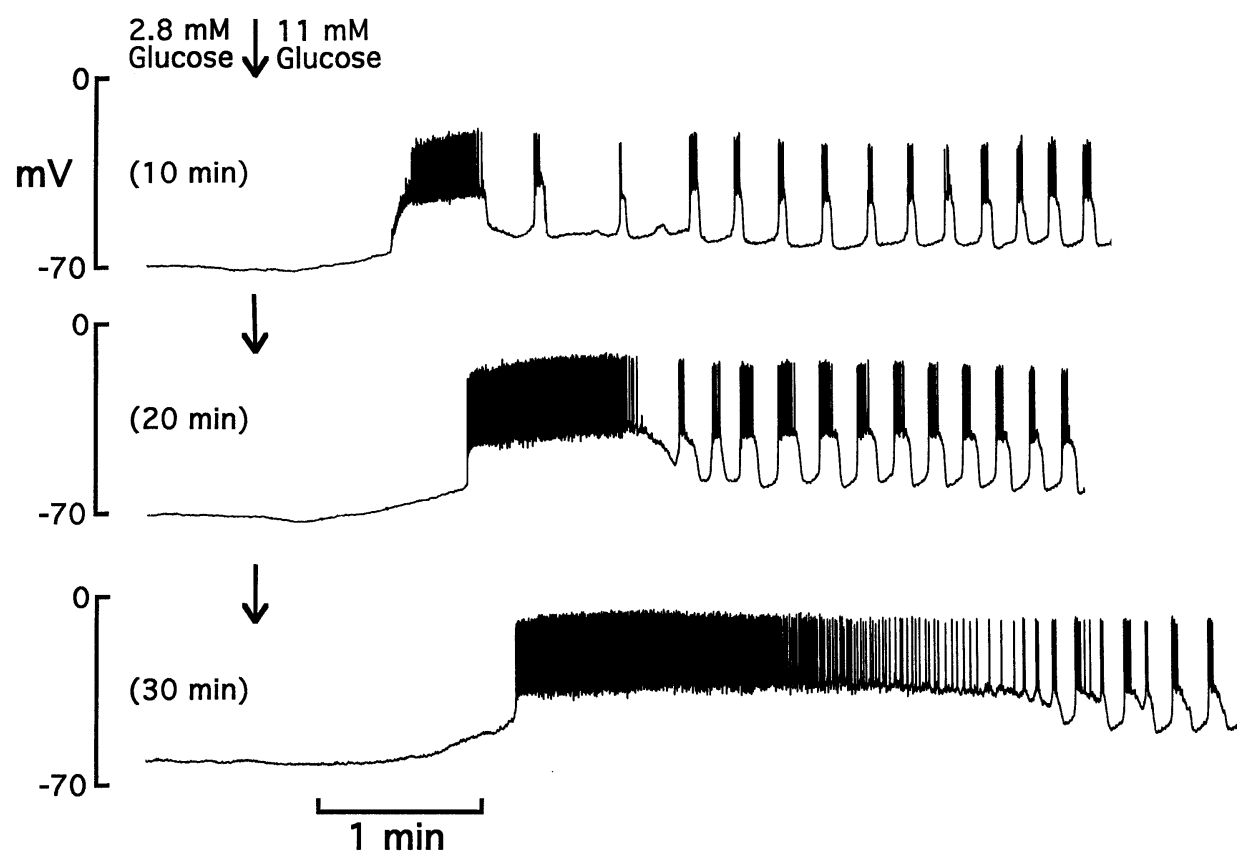

Fig. 4. Effect of duration of exposure to basal glucose on Phase 1 electrical activity. Segments of a continuous recording of $\beta$-cell membrane potential show Phase 1 induced by $11 \mathrm{~mm}$ glucose following exposure to $2.8 \mathrm{~mm}$ glucose for $10 \mathrm{~min}$ (top), $20 \mathrm{~min}$ (middle), and $30 \mathrm{~min}$ (bottom). Twenty-five min elapsed between recording of top and middle traces, and 35 min elapsed between recording of middle and bottom traces.

29 and $65 \mathrm{sec}$, respectively. When stimulatory glucose was reapplied after thirty min in low glucose (lower trace), Phase 1 consisted of an initial period of continuous spiking lasting for $100 \mathrm{sec}$ followed by very high frequency oscillations, similar to those induced by muscarinic agonists (Bertram et al., 1995). In control experiments, Phase 1 duration was the same when $11 \mathrm{~mm}$ glucose was applied following consecutive 10-min periods $(n=6)$ or 20 -min periods $(n=2)$ in $2.8 \mathrm{~mm}$ glucose (data not shown). Thus the increased Phase 1 duration observed in Fig. 4 and similar experiments does not reflect a "priming" effect of repeated glucose exposures (Grill, Adamson \& Cerasi, 1978). The latency, defined as the time from addition of glucose to the beginning of Phase 1, also increased with time of exposure to basal glucose.

Similar results were observed in several other experiments, however, most impalements did not last long enough to make multiple Phase 1 measurements following long withdrawal times. Figure 5 is a plot of Phase 1 duration vs. withdrawal time using data from many $\beta$-cells. A prolonged transient could be observed following exposure to basal glucose for as little as $40 \mathrm{sec}$, and Phase 1 duration increased to about $25 \mathrm{sec}$ following a reduction in glucose concentration for only $2 \mathrm{~min}$. There was then little change in Phase 1 duration until the glucose level had been lowered for about $10 \mathrm{~min}$, at which point the curve rose steeply with time of exposure to basal glucose. Then mean Phase 1 duration following 2

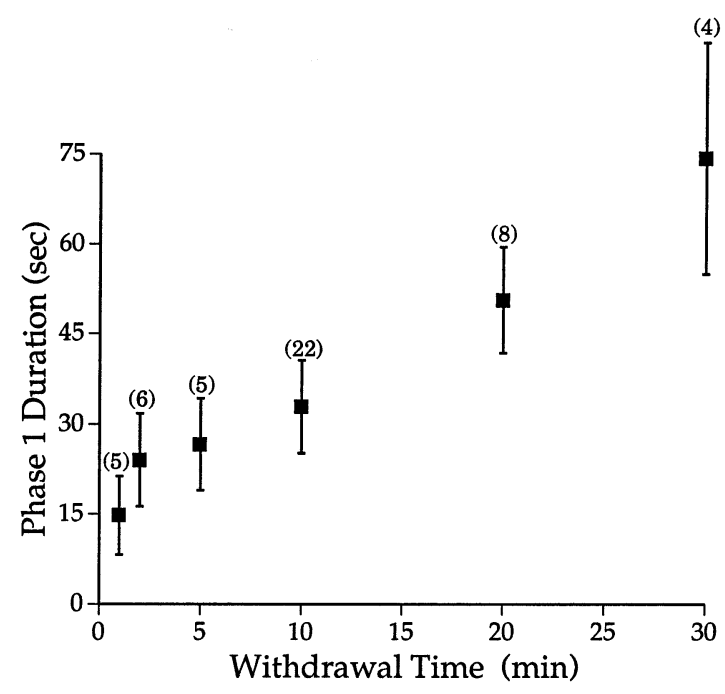

Fig. 5. Relationship between Phase 1 duration and glucose withdrawal time. The number of observations is given in parenthesis near each point. Significance levels: $P<0.002$ ( 2 min vs. $1 \mathrm{~min}$ ), $P<0.0001$ (20 $\min v s .10 \mathrm{~min}), P<0.01$ (30 $\mathrm{min} v s .20 \mathrm{~min})$.

min in basal glucose was significantly longer than that observed after $1 \mathrm{~min}$ at the lower concentration $(P<$ 0.002). Similarly, the mean Phase 1 duration after 20 min in low glucose was significantly different from that following $10(P<0.0001)$ and $30(P<0.01) \mathrm{min}$ in basal glucose. 



Fig. 6. Simulation result: effect of refilling calcium stores on Phase 1. (A) Membrane Potential, (B) intracellular calcium, (C) endoplasmic reticulum calcium responses of the model. Glucose removal and addition were simulated as in Fig. 2. The extracellular $\mathrm{K}^{+}$concentration was increased $\left(V_{\mathrm{K}}\right.$ changed from -70 to $-50 \mathrm{mV}$ ) where indicated. Upon re-addition of glucose, bursting recovered with a Phase 1 of 9-sec duration, only $5 \mathrm{sec}$ longer than the active phase of a typical model burst.

Modulation of Phase 1 Duration by Manipulating Calcium Store Filling

The model predicts that Phase 1 duration can be altered by manipulating the level of filling of intracellular calcium stores prior to addition of glucose. Fig. 6 shows a simulation in which a model $\beta$-cell was exposed to 15 $\mathrm{mm} \mathrm{KCl}$ (simulated by changing $V_{K}$ to $-50 \mathrm{mV}$ ) during a 20 -minute period in basal glucose. The elevated potassium depolarized the membrane (Fig. 6A) and stimulated calcium influx through voltage-gated calcium channels. The resulting increase in intracellular calcium level (Fig. $6 B$ ) forced the filling of the ER despite the presence of basal glucose, so the ER calcium concentration was higher at the end of the 20-min period in basal glucose than the control simulation (not shown). When glucose was reapplied (by lowering $g_{\mathrm{K}(\mathrm{ATP})}$ ), the stores quickly refilled to their steady-state level, and Phase 1 duration was only $9 \mathrm{sec}$ (compare to simulation results of Fig. 3, where Phase 1 duration following $20 \mathrm{~min}$ in basal glucose was $40 \mathrm{sec}$ ).

Figure 7 shows experimental data corresponding to the simulation presented in Fig. 6. During an initial exposure to $2.8 \mathrm{~mm}$ glucose (20-min duration), the $\mathrm{K}^{+}$concentration in the perifusate was increased to $15 \mathrm{~mm}$ for $10 \mathrm{~min}$, from $t=6$ to $t=16 \mathrm{~min}$ (Fig. 7A, top). As in Fig. $6 A$, the elevated $\mathrm{K}^{+}$induced membrane depolarization, which facilitates calcium entry (Atwater et al., 1981) to refill intracellular stores (Nadal, Valdeolmillos \& Soria, 1994). As a control, the same islet was again exposed to basal glucose for $20 \mathrm{~min}$, with normal (5 mM) $\mathrm{K}^{+}$present throughout $(7 A$, lower trace). Figure $7 B$ shows the Phase 1 electrical activity from Fig. $7 A$ on an expanded time scale. Phase 1 duration was $38 \mathrm{sec}$ following exposure to $15 \mathrm{mM} \mathrm{K}^{+}$, and $57 \mathrm{sec}$ in the control case. A similar result was observed in one other experiment in which the impalement lasted long enough to obtain a test measurement and a control measurement. A total of 4 cells were exposed to high $\mathrm{K}^{+}$during a 20-min period in basal glucose. As shown in Fig. 7C, the mean Phase 1 duration following this treatment $(23 \pm 10$ sec) was significantly shorter $(P<0.005)$ than that of a control group exposed to low glucose for 20 min with 5 $\mathrm{mM} \mathrm{K}^{+}$present throughout $(51 \pm 9 \mathrm{sec}, n=8)$.

Figure $8 A$ illustrates an experimental protocol used to accelerate emptying of calcium stores during exposure to basal glucose. The glucose concentration was first lowered to $2.8 \mathrm{~mm}$ for $10 \mathrm{~min}$ in normal Krebs solution as a control (upper trace). During a second period in basal glucose, calcium was removed from the medium for the final $5 \mathrm{~min}$. This procedure is expected to reduce the residual calcium influx and thus accelerate emptying of intracellular stores (Worley et al., 1994a). Figure 8B shows that Phase 1 duration was longer after exposure to calcium-free solution $(50 \mathrm{sec})$ compared to the control $(29 \mathrm{sec})$. Four other cells were exposed to the protocol illustrated in Fig. 8A. In each case, Phase 1 duration after calcium had been removed was longer than the control. The mean Phase 1 duration after exposure to the calcium-free medium $(52 \pm 11.5 \mathrm{sec})$ was significantly longer $(P<0.001)$ than the control $(34 \pm 10 \mathrm{sec})$, as shown in Fig. $8 C$. In two additional experiments, Phase 1 duration did not increase when the $\mathrm{Mg}^{2+}$ concentration was raised to $10 \mathrm{~mm}$ without removal of calcium (data not shown). This indicates that the increased Phase 1 duration observed in Fig. 8 and similar experiments results from removal of calcium from the perifusate rather than addition of magnesium. These results are in agreement with model simulations (not shown).

Phase 1 duration should also increase if calcium store emptying is accelerated with a muscarinic agonist. Figure 9 shows the effect of adding carbachol (CCh) during low glucose exposure. As in Fig. 8, the cell was first exposed to low glucose for $10 \mathrm{~min}$ as a control. During the second 10-min period in low glucose, $10 \mu \mathrm{M}$ carbachol was added to the medium (Fig. 9A). The muscarinic agonist was expected to accelerate the emptying 

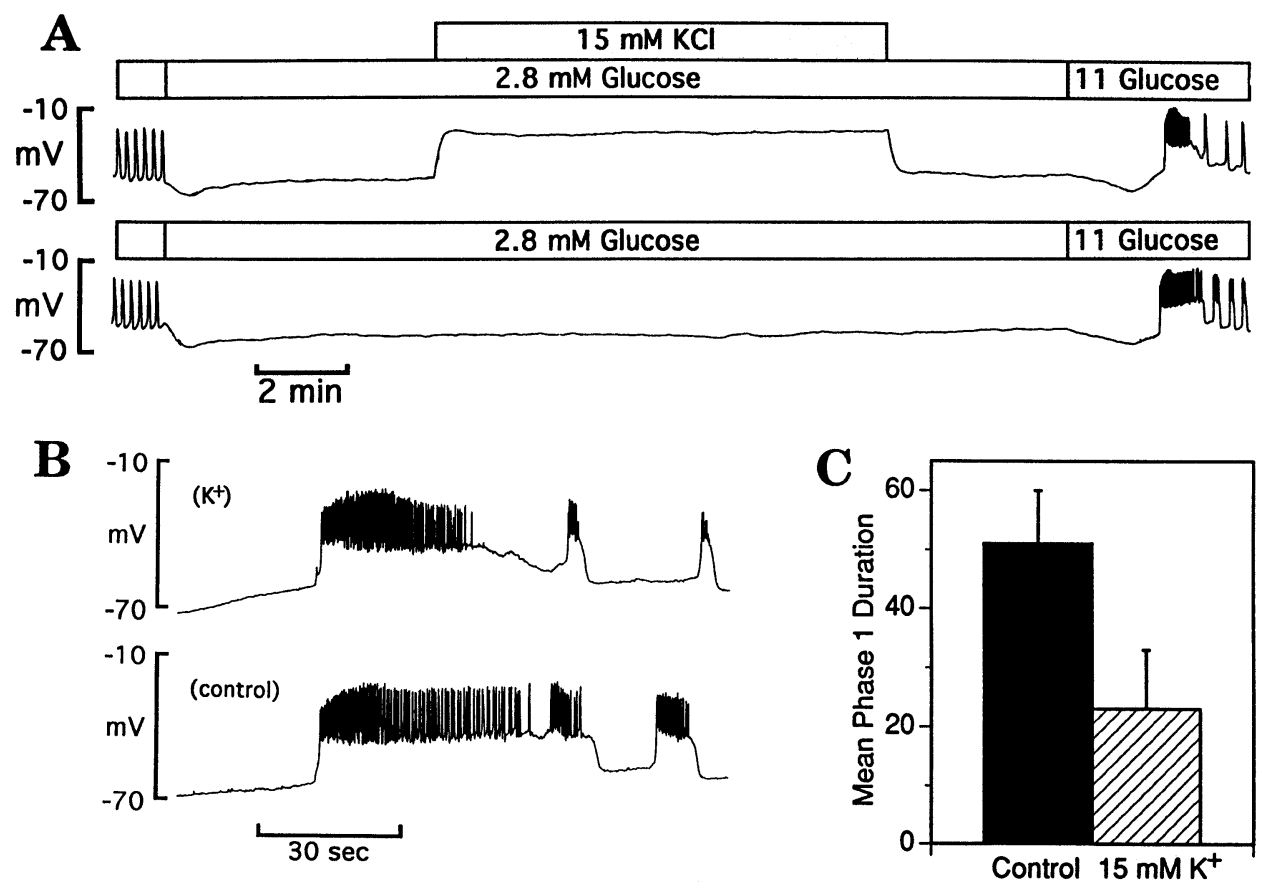

Fig. 7. Refilling intracellular calcium stores reduces Phase 1 duration. $(A)$ Protocol used to refill calcium stores in the presence of basal glucose. The islet was exposed to $2.8 \mathrm{~mm}$ glucose for two consecutive 20 -min periods. During the first exposure, the $\mathrm{K}^{+}$concentration in the perifusate was raised to $15 \mathrm{~mm}$ for $10 \mathrm{~min}$ to depolarize the cell and stimulate calcium influx (top). The second exposure served as a control (bottom). (B) The transient electrical activity induced by glucose in the two traces of $(A)$ is shown on an expanded time scale. Phase 1 was shorter following exposure to $15 \mathrm{~mm} \mathrm{~K}^{+}$. (C) Mean Phase 1 duration from four cells exposed to $15 \mathrm{~mm} \mathrm{~K}^{+}$during a 20-min basal glucose exposure (hatched bar) was shorter $(P<0.005)$ than that of 8 cells exposed to low glucose for $20 \mathrm{~min}$ in normal potassium (solid bar).

of calcium stores similarly to low calcium exposure. However, as illustrated in Fig. 9B, the Phase 1 duration following $\mathrm{CCh}$ application was actually shorter than the control. Many experiments were done using $\mathrm{CCh}$ or acetylcholine (ACh), at concentrations ranging from 1 to $100 \mu \mathrm{M}$ and with various exposure times. In most cases the Phase 1 duration following exposure to a muscarinic agonist was the same or slightly shorter than the control. The nature of this discrepancy with the model prediction is discussed below.

\section{Phase 1 Following Diazoxide ExPosure}

Diazoxide (Dz), a sulfonylurea agonist of $\mathrm{K}_{\mathrm{ATP}}$ channels (Sturgess et al., 1985), hyperpolarizes the $\beta$-cell membrane in the presence of $11 \mathrm{~mm}$ glucose without depleting intracellular calcium stores (Gylfe, 1991). Fig. 10 shows that when $\mathrm{Dz}$ was removed following an 8-min exposure, bursting recovered rapidly with no prolonged Phase 1. Similar results were seen in three other experiments using various $\mathrm{Dz}$ levels and exposure times ranging from 2 to $10 \mathrm{~min}$.

\section{Discussion}

Although step changes in glucose level do not occur physiologically, the absence of the acute insulin response in NIDDM and prior to development of IDDM indicates that the mechanism underlying Phase 1 is important for maintenance of glucose homeostasis. Here we focus on the prediction of a mathematical model (Bertram et al., 1995) that $I_{\text {CRAN }}$ is involved in the biphasic electrical response to glucose. The key to this response is activation of $I_{\text {CRAN }}$ by ER emptying in basal glucose, and deactivation of $I_{\text {CRAN }}$ by ER filling in stimulatory glucose (Fig. 2). Although ER calcium concentration and $I_{\text {CRAN }}$ have not been measured during glucose-induced $\beta$-cell electrical activity, the demonstration here that Phase 1 duration is related to the filling state of $\beta$-cell calcium stores provides strong indirect evidence that $I_{\text {CRAN }}$ mediates the biphasic response. Furthermore, the broad agreement between the experimental results and the predictions of the model provides evidence that the model accurately describes $\beta$-cell calcium handling and the role of $I_{\text {CRAN }}$ in $\beta$-cell electrical activity. The results are discussed below in terms of the model predictions, and alternative mechanisms are considered.

\section{Effect of Time of Exposure to Basal Glucose on Phase 1 Electrical Activity}

The mathematical model predicts that the duration of Phase 1 upon stimulation with $11 \mathrm{~mm}$ glucose will in- 
A


Fig. 8. Phase 1 duration increases following emptying of calcium stores. $(A)$ Protocol used to accelerate emptying of calcium stores in the presence of basal glucose. The glucose concentration was first lowered for $10 \mathrm{~min}$ as a control (top). During a second 10-min period in basal glucose, calcium was removed from the perifusate for the final $5 \mathrm{~min}$ (bottom). $(B)$ The glucose-induced transient electrical activity from the two traces of $(A)$ is shown on an expanded time scale. Phase 1 was longer following exposure to 0 calcium. $(C)$ In five total experiments, mean Phase 1 duration following $0 \mathrm{Ca}^{2+}$ exposure (hatched bar) was longer $(P<0.001)$ than the control recordings (solid bar).

crease with the duration of the immediately proceeding exposure to basal glucose (Fig. 3). This occurs because the calcium stores empty further (Fig. 2C) and take longer to refill when glucose is reapplied. The idea that $I_{\text {CRAN }}$ can be active in the presence of low glucose without affecting membrane potential (Figs. $2 A$ and $E$ ) is consistent with data showing that high doses of muscarinic agonists and thapsigargin have little or no effect on $\beta$-cell membrane potential when applied with substimulatory concentrations of the sugar (Worley et al., 1994a; Bertram et al., 1995; Bordin et al., 1995).

Figures 4 and 5 show experimental data in support of this model prediction. Interestingly, following very long exposure to basal glucose, steady-state bursting is preceded by high frequency oscillations resembling those induced by muscarinic agonists (Fig. 4, bottom). We suggest that during the initial long period of continuous spiking (driven by $I_{\text {CRAN }}$ ), intracellular calcium reached sufficient levels to activate calcium-activated potassium channels $\left(\mathrm{K}_{\mathrm{Ca}}\right)$, causing the rapid, shallow repolarizations seen at the end of Phase 1 (Bertram et al., 1995).

The steep increase in Phase 1 duration following exposure to basal glucose for $10 \mathrm{~min}$ or longer (Fig. 5) is in accord with the behavior of the model (Fig. 3). The model, as currently formulated, does not account for the rise in Phase 1 duration following short ( $<2 \mathrm{~min}$ ) exposure to low glucose because there is little activation of $I_{\text {CRAN }}$ during this time (Fig. $2 E$ ). The nature of Phase 1 following short reductions in glucose level remains to be fully characterized, but could result from activation of $I_{\text {CRAN }}$ if there is a component of rapid calcium efflux from the ER upon removal of glucose, or if the $I_{\text {CRAN }}$ activation curve is steeper at high ER calcium levels than what is postulated in the model. The remainder of the experiments in this study focused on the Phase $1 \mathrm{ob}-$ served after relatively long reductions in glucose concentrations.

Figure 4 shows that the latency (delay from addition of glucose to onset of Phase 1) also increases with time of exposure to basal glucose. This was a consistent experimental observation when the glucose concentration was lowered for $5 \mathrm{~min}$ or longer. We model glucose addition as a pure step $\left(\mathrm{K}_{\mathrm{ATP}}\right.$ conductance decreases instantaneously) to focus on phenomena that can be attributed solely to filling of the ER, but experimentally there could be a delay between addition of glucose and reduction of $\mathrm{K}_{\mathrm{ATP}}$ conductance. The latency is not likely to be related to $I_{\text {CRAN }}$, since activation of this current in basal glucose should have the opposite effect of increasing 

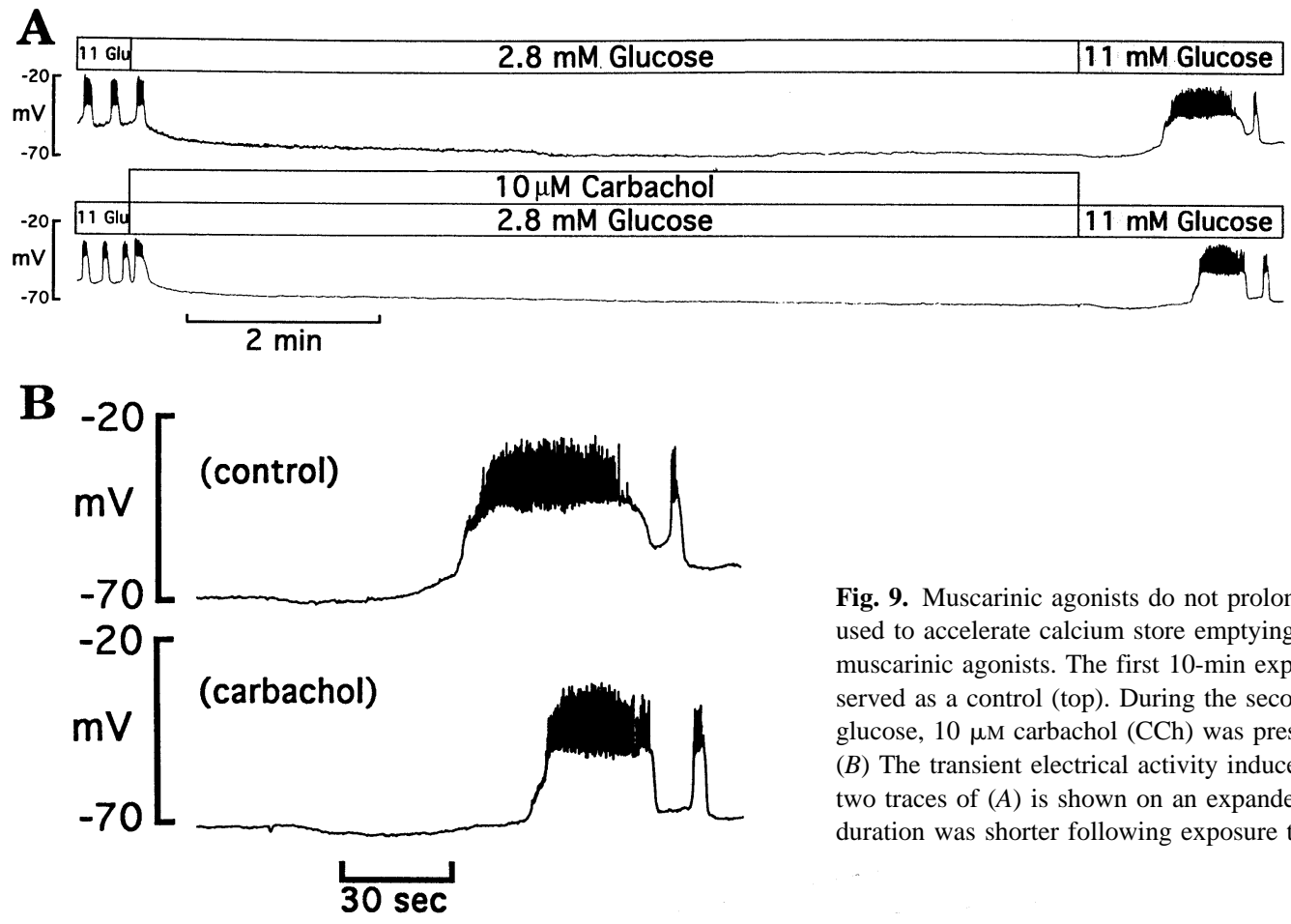

Fig. 9. Muscarinic agonists do not prolong Phase 1. (A) Protocol used to accelerate calcium store emptying in basal glucose with muscarinic agonists. The first 10-min exposure to $2.8 \mathrm{~mm}$ glucose served as a control (top). During the second period in $2.8 \mathrm{~mm}$ glucose, $10 \mu \mathrm{M}$ carbachol (CCh) was present throughout (bottom). $(B)$ The transient electrical activity induced by $11 \mathrm{~mm}$ glucose in the two traces of $(A)$ is shown on an expanded time scale. Phase 1 duration was shorter following exposure to the muscarinic agonist.

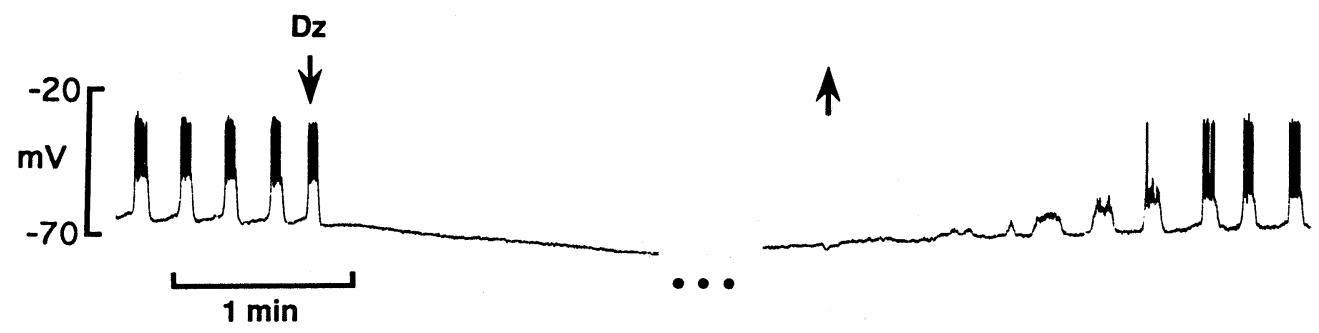

Fig. 10. Electrical activity following exposure to diazoxide. Stimulatory glucose $(11 \mathrm{~mm})$ was present throughout the recording. Left side: $50 \mu \mathrm{M}$ diazoxide (Dz), added at the arrow, hyperpolarized the cell in the presence of the sugar. Right side: Dz was removed at the arrow, and bursting recovered without a prolonged Phase 1. Six minutes elapsed between recording of the left and right sides of the figure.

excitability. Therefore, further experimentation to determine the mechanism responsible for the increased latency in Fig. 4 was not undertaken.

\section{Effect of Manipulating Calcium Store Filling on Phase 1 DuRATION}

The model predicts that Phase 1 duration will be reduced if the cell is exposed to high potassium during the period in basal glucose (Fig. 6), because the membrane depolarizes and calcium influx refills the stores (Atwater et al., 1981; Roe et al., 1993; Nadal et al., 1994). Experimentally, raising the $\mathrm{K}^{+}$concentration to $15 \mathrm{~mm}$ during basal glucose exposure shortened the ensuing Phase 1 (Fig. 7).

One difficulty in interpreting the experimental results is separating the effect of refilled calcium stores from that of elevated intracellular calcium, which inhibits glucose-induced electrical activity (Atwater, Rosario \& Rojas, 1983; Santos et al., 1992; Rosario et al., 1993; Bertram et al., 1995). For example, following elevation of extracellular $\mathrm{K}^{+}$in the presence of $11 \mathrm{~mm}$ glucose, the $\beta$-cell hyperpolarizes and bursts are inhibited transiently (Dawson, Atwater \& Rojas, 1984). This result most likely reflects an effect of elevated intracellular calcium on ion channels (Dawson et al., 1984; Rosario et al., 1993) or metabolism (Keizer \& Magnus, 1989). Potential effects of elevated intracellular calcium were avoided in these experiments by returning the $\mathrm{K}^{+}$level to $5 \mathrm{mM}$ for 4 to $8 \mathrm{~min}$ prior to the addition of glucose (Fig. 7A). Studies with the fluorescent calcium indicator indo-1 have shown that in the presence of $3 \mathrm{~mm}$ glucose, $\beta$-cell intracellular calcium recovers to control levels within 1 to $3 \mathrm{~min}$ following exposure to $15 \mathrm{~mm} \mathrm{KCl}$ (Nadal et al., 
1994). Furthermore, Dawson et al. (1984) showed that bursting electrical activity recovers in less than $2 \mathrm{~min}$ following exposure to $50 \mathrm{~mm} \mathrm{~K} \mathrm{~K}^{+}$in the presence of 11 mM glucose. Also, we never observed increased latency, indicating inhibition of electrical activity by elevated $\mathrm{Ca}_{i}$, when extracellular $\mathrm{K}^{+}$was returned to $5 \mathrm{mM} 4$ to 8 min prior to increasing the glucose level. Thus intracellular calcium was probably not elevated when glucose was applied in Fig. 7A, and the reduced Phase 1 duration following exposure to elevated $\mathrm{K}^{+}$most likely resulted from calcium store refilling.

The converse experimental manipulation, accelerating the rate of calcium store emptying, was accomplished by removing calcium from the extracellular medium. This process increases the rate of calcium efflux from the ER (Roe et al., 1993) with very minor reduction in intracellular calcium (Rojas et al., 1994). Phase 1 duration following exposure to basal glucose for $10 \mathrm{~min}$ was longer when calcium was removed for the last $5 \mathrm{~min}$ as compared to control recordings (Fig. 8), consistent with simulations (not shown).

Calcium stores can also be emptied in the absence of glucose by muscarinic agonists (Rojas et al., 1994). However, muscarinic agonists did not increase the duration of Phase 1 (Fig. 9). Three possible explanations for this discrepancy with the model are: (i) efflux of calcium from intracellular stores was not accelerated with this protocol or the stores had refilled by the time electrical activity commenced; (ii) store depletion was greater but $I_{\text {CRAN }}$ did not activate under these conditions; and (iii) muscarinic agonists may have inhibitory effects on $\beta$-cell activity in basal glucose that overcome the stimulatory effect of activation of $I_{\mathrm{CRAN}}$. As evidence for the latter, Sánchez-Andrés and Soria (1991) reported that when $11 \mathrm{~mm}$ glucose was applied simultaneously with 1 $\mu \mathrm{M}$ CCh following exposure to $3 \mathrm{~mm}$ glucose (time not specified), the latency was dramatically increased, Phase 1 was abolished, and insulin secretion was temporarily inhibited. The mechanism underlying this inhibition is not known, but possibilities include elevated intracellular calcium, metabolic inhibition, and direct effects of $\mathrm{CCh}$ on ion channels. Inactivation of $I_{\mathrm{CRAN}}$ or desensitization of muscarinic receptors are not likely to be responsible for the inability of $\mathrm{CCh}$ to increase Phase 1 duration, since the effects of $\mathrm{Tg}$ and $\mathrm{CCh}$ on $\beta$-cell electrical activity can be observed for at least $60 \mathrm{~min}$ (Bertram et al., 1995), and short exposures to CCh also did not enhance Phase 1 duration (data not shown).

The key point is that the failure of $\mathrm{CCh}$ to increase Phase 1 duration does not necessarily invalidate the hypothesis that $I_{\mathrm{CRAN}}$ is responsible for this response. Muscarinic agonists activate complex signaling pathways in the $\beta$-cell, not all of which are well understood, especially in basal glucose. Therefore, it is possible that some metabolic or ionic effect of $\mathrm{CCh}$ that is not accounted for in the model is responsible for the discrep- ancy between the theoretical prediction and the experimental result.

\section{EleCtrical Activity Following DiAZOXIDE EXPOSURE}

The sulfonylurea diazoxide (Dz) activates $\mathrm{K}_{\mathrm{ATP}}$ channels and hyperpolarizes the $\beta$-cell membrane in the presence of $11 \mathrm{~mm}$ glucose. However, under this condition, unlike the case in which the glucose concentration is lowered, intracellular calcium stores remain relatively full (Gylfe, 1991). The most likely explanation for this observation is that calcium sequestering by the SERCA pump is enhanced in the presence of $11 \mathrm{~mm}$ glucose (Nadal et al., 1994; Roe et al., 1994a). Glucose also activates voltageindependent ion channels (Rojas et al., 1990), which could carry calcium into the cell to reduce the rate of store emptying in the presence of diazoxide. In any case, $I_{\text {CRAN }}$ should not activate in the presence of Dz and 11 $\mathrm{mm}$ glucose, so according to our hypothesis there should be no prolonged Phase 1 after Dz is removed. As shown in Fig. 10, glucose-induced bursting recovered with no Phase 1 when Dz was removed after 8 min of exposure. This result supports the hypothesis that calcium stores must empty ( $I_{\text {CRAN }}$ must activate) to produce Phase 1 .

\section{Alternative Mechanisms for Phase 1}

The mathematical model reveals that the biphasic electrical response to glucose depends on a negative feedback that develops slowly during the initial spiking phase. For example, any depolarizing current that activates slowly when the glucose level is lowered and deactivates slowly when the glucose level is increased would suffice to produce a biphasic response that behaves according to Fig. 3. The experimental results presented here, showing that Phase 1 duration is sensitive to the state of filling of intracellular calcium stores, support the hypothesis that the current mediating the biphasic response is indeed a calcium release-activated current.

Currents activated directly by intracellular calcium are unlikely to mediate Phase 1 . Intracellular calcium rises quickly to a plateau at the start of Phase 1 (Roe et al., 1993; Santos et al., 1991), so hyperpolarizing effects of calcium accumulation are unlikely to be involved in termination of the transient. Intracellular acidification and alkalinization induce $\beta$-cell depolarization and hyperpolarization, respectively (Pace, Tarvin \& Smith, 1983), probably by affecting the open probability of $\mathrm{K}_{\text {ATP }}$ channels (Misler, Gillis \& Tabcharani, 1989). Thus, early reports that glucose induces an initial acidification followed by progressive alkalinization of the $\beta$-cell (Lynch et al., 1989) suggest a role of $\mathrm{pH}_{i}$ in Phase 1. However, elevated $\mathrm{KCl}$ has been shown to reduce $\mathrm{pH}_{i}$ (Deelers, Lebrun \& Malaisse, 1985), so if $\mathrm{pH}_{i}$ were responsible for Phase 1, we would expect a prolongation of the transient by prior exposure to $\mathrm{KCl}$, rather than the 
shortening shown in Fig. 6. Furthermore, Salgado et al. (1996) recently reported that $\mathrm{pH}_{i}$ in single $\beta$-cells decreases following the glucose-induced increase in intracellular calcium, arguing against a role for alkalinization in termination of Phase 1. Finally, while glucoseinduced second messengers such as protein kinase $\mathrm{C}$ may affect the magnitude of the secretory response during each phase (Taguchi et al., 1995), it is doubtful that the production of such a metabolic signal would be affected by the experimental manipulations performed in this study.

We have also considered the possibility that alternative calcium handling dynamics underlie the role of $I_{\text {CRAN }}$ in Phase 1. In particular, recent evidence for depolarization-dependent calcium release in $\beta$-cells (Roe et al., 1993) and insulin secreting cell lines (Gromada, Frøkjær-Jensen \& Dissing, 1996) has led to the suggestion that $I_{\text {CRAN }}$ participates in Phase 1 by activating rapidly at the beginning of the transient rather than during the basal glucose exposure as we suggest. While appropriately-timed transients in $\mathrm{IP}_{3}$ production or calcium release upon increasing the glucose concentration could activate $I_{\text {CRAN }}$ to produce Phase 1 , the results with diazoxide argue against a major role for voltage-dependent calcium release in Phase 1. Since calcium stores remain full in the presence of diazoxide and glucose, the depolarization following removal of the drug would stimulate calcium release, resulting in activation of $I_{\text {CRAN }}$ and a prolonged Phase 1.

\section{Alternative Roles FOR $\mathrm{I}_{\text {CRAN }}$}

In the model described in this paper, glucose-induced bursting is driven by slow inactivation of voltage-gated calcium channels. Although there is no definitive proof that this is the process underlying bursting, there is no reason to believe that models incorporating different burst mechanisms but similar calcium handling dynamics to those described here would not produce the same biphasic behavior when $I_{\mathrm{CRAN}}$ is incorporated.

Recent models have begun to explore the possibility that oscillations in calcium release-activated current could drive bursting electrical activity in neurons and pancreatic $\beta$-cells (Chay, 1996; L. Xu and C.L. Stokes, 1996, submitted). In our model, in contrast, $I_{\text {CRAN }}$ does not change enough on the time scale of the burst to control steady-state oscillations in electrical activity. $I_{\text {CRAN }}$ can, however, act as a depolarizing background current that affects the threshold glucose concentration for bursting as well as the burst frequency and plateau fraction. The model of $\mathrm{Xu}$ and Stokes accounts for the electrical effects of cAMP-elevating agents (based on the hypothesis that cAMP activates ryanodine receptors to stimulate calcium release), and the slow depolarization induced by thapsigargin. The Chay model captures some aspects of the $\mathrm{Ca}_{i}$ time course that our model does not, and can produce a wider range of burst frequencies. It remains to be seen whether these models can account for the full range of ER-dependent phenomena, including the muscarinic response in $11 \mathrm{~mm}$ glucose (Bertram et al., 1995) and the biphasic transients studied here. In addition to the latter, our model accounts for several other experimental observations (not shown). First, when the glucose concentration is suddenly lowered from one stimulatory concentration to another, a long silent phase often precedes the resumption of bursting electrical activity (Beigelman, Ribalet \& Atwater, 1977; Cook, 1984; Henquin, 1992). In our model this "reverse" Phase 1 occurs when glucose is lowered to a level at which the $\mathrm{K}_{\text {ATP }}$ current is sufficient to bring the membrane just below the threshold for spike activity. The long silent period reflects the time required for the ER to partially empty (owing to reduced calcium influx) and activate $I_{\text {CRAN }}$ to bring the membrane back to the threshold for bursting. Also, when exposed to a slow ramp increase in glucose concentration, $\beta$-cell electrical activity (Beigelman et al., 1977) and secretion (Grodsky, 1972) occur without Phase 1 . The model behaves similarly because the ER progressively fills as the membrane gradually depolarizes, and $I_{\text {CRAN }}$ is largely deactivated by the time electrical activity begins. Finally, $\beta$-cells in islets from $\mathrm{db} / \mathrm{db}$ mice often spike continuously at stimulatory glucose concentrations rather than bursting (Meissner \& Schmidt, 1976). Based on the observation that $\beta$-cells in $\mathrm{db} / \mathrm{db}$ mouse islets do not express SERCA pumps (Roe et al., 1994b), we interpret this monophasic behavior as a Phase 1 that never terminates because calcium stores cannot refill. The same behavior is observed in normal mouse $\beta$-cells that have been treated with thapsigargin to prevent calcium uptake into the ER (Worley et al., 1994b).

In summary, we have provided experimental and theoretical evidence that $I_{\text {CRAN }}$ mediates the biphasic response of mouse islet $\beta$-cells to glucose. With the exception of results with muscarinic agonists, the excellent agreement between the majority of the experimental data and predictions of the mathematical model provides evidence that the model accurately describes the role of $I_{\text {CRAN }}$ in $\beta$-cell electrophysiology.

The authors thank Drs. Bernat Soria and Franz Martin for sharing unpublished data on $\beta$-cell calcium handling. R.B. and A.S. performed simulations. D.M. was supported by a National Institutes of Health training grant to the JHU Dept. Biomed. Eng. (5 T32 GM7057) and by a Greenwall Foundation award to N.F.S.

\section{References}

Atwater, I., Dawson, C.M., Eddlestone, G.T., Rojas, E. 1981. Voltage noise measurements across the pancreatic $\beta$-cell membrane: Calcium channel characteristics. J. Physiol. 314:195-212

Atwater, I., Ribalet, B., Rojas, E. 1978. Cyclic changes in potential and resistance of the $\beta$-cell membrane induced by glucose in islets of Langerhans from mouse. J. Physiol. 278:117-139 
Atwater, I., Rosario, L., Rojas, E. 1983. Properties of the Ca-activated $\mathrm{K}^{+}$channel in pancreatic $\beta$-cells. Cell Calcium 4:451-461

Beigelman, P.M., Ribalet, B., Atwater, I. 1977. Electrical activity of mouse pancreatic $\beta$-cells: II. Effects of glucose and arginine. $J$. Physiol. 73:201-217

Bertram, R., Smolen, P., Sherman, A., Mears, D., Atwater, I., Martin, F., Soria, B. 1995. A role for calcium release activated current (CRAC) in cholinergic modulation of electrical activity in pancreatic $\beta$-cells. Biophys. J. 68:2323-2332

Bode, H.P., Göke, B. 1994. Protein kinase C activates capacitative calcium entry in the insulin secreting cell line RINm5F. FEBS Lett. 339:307-311

Bordin, S., Boschero, A.C., Carneiro, E.M., Atwater, I. 1995. Ionic mechanisms involved in the regulation of insulin secretion by muscarinic agonists. J. Membrane Biol. 148:177-184

Cerasi, E. 1988. Characteristics of insulin secretion of non-insulin dependent diabetes. In: Pathogenesis of Non-Insulin Dependent Diabetes Mellitus. V. Grill and S. Efendic, Editors. pp. 107-118. Raven Press, New York

Chay, T.R. 1996. Modeling slowly bursting neurons via calcium store and voltage-independent calcium current. Neural Comp. 8:951-978

Colman, P.G., Eisenbarth, G.S. 1987. Immunotherapy in type 1 diabetes: Approaches to prevention and treatment. Postgrad. Med. 81:146-155

Cook, D.L. 1984. Electrical pacemaker mechanisms of pancreatic islet cells. Fed. Proc. 43:2368-2372

Curry, D.L., Bennett, L.L., Grodsky, G.M. 1968. Dynamics of insulin secretion by the perfused rat pancreas. Endocrinology 83:572-584

Dawson, C.M., Atwater, I., Rojas, E. 1984. The response of pancreatic B-cell membrane potential to potassium-induced calcium influx in the presence of glucose. Quart. J. Exp. Physiol. 69:819-830

Deelers, M., Lebrun, P., Malaisse, W.J. 1985. Nutrient-induced changes in the $\mathrm{pH}$ of pancreatic islet cells. Horm. Met. Res. 17:391395

Fasolato, C., Innocenti, B., Pozzan, T. 1994. Receptor-activated $\mathrm{Ca}^{2+}$ influx: how many mechanisms for how many channels? Trends Pharm. Sci. 15:77-83

Grill, V., Adamson, U., Cerasi, E. 1978. Immediate and time-dependent effects of glucose on insulin release from rat pancreatic tissue. $J$. Clin. Invest. 61:1034-1043

Grodsky, G.M. 1972. A threshold distribution hypothesis for packet storage of insulin and its mathematical modeling. J. Clin. Invest. 51:2047-2059

Grodsky, G.M. 1989. A new phase of insulin secretion. How will it contribute to our understanding of $\beta$-cell function? Diabetes 38:673-678

Gromada, J., Frøkjær-Jensen, J., Dissing, S. 1996. Glucose stimulates voltage- and calcium-dependent inositol triphosphate production and intracellular calcium mobilization in insulin secreting $\beta$ TC3 cells. Biochem. J. 314:339-345

Gylfe, E. 1991. Carbachol induces sustained glucose-dependent oscillations of cytoplasmic $\mathrm{Ca}^{2+}$ in hyperpolarized pancreatic b cells. Pfluegers Arch. 419:639-643

Henquin, J.C. 1992. Adenosine triphosphate-sensitive $\mathrm{K}^{+}$channels may not be the sole regulators of glucose-induced electrical activity in pancreatic B-cells. Endocrinology 131:127-131

Hofer, A.M., Machen, T.E. 1993. Technique for in situ measurement of calcium in intracellular inositol 1,4,5-triphosphate-sensitive stores using the fluorescent indicator mag-fura-2. Proc. Natl. Acad. Sci. USA 90:2598-2602

Hoth, M., Penner, R. 1992. Depletion of intracellular calcium stores activates a calcium current in mast cells. Nature 355:353-356

Keizer, J., Magnus, G. 1989. ATP-sensitive potassium channel and bursting in the pancreatic beta cell: A theoretical study. Biophys. J. 56:229-242

Lacy, P.E., Walker, M.M., Fink, C.J. 1972. Perifusion of isolated rat islets in vitro: participation of the microtubular system in the biphasic release of insulin. Diabetes 21:987-998

Leech, C.A., Holtz IV, G.G., Habener, J.F. 1994. Voltage-independent calcium channels mediate slow oscillations of cytosolic calcium that are glucose dependent in pancreatic $\beta$-cells. Endocrinology 135:365-372

Li, Y.-X., Rinzel, J. 1994. Equations for $\mathrm{InsP}_{3}$ receptor-mediated $\left[\mathrm{Ca}^{2+}\right]$ oscillations derived from a detailed kinetic model: a Hodgkin-Huxley like formalism. J. Theor. Biol. 166:461-473

Lynch, A.M., Meats, J.E., Best, L., Tomlinson, S. 1989. Effects of nutrient and non-nutrient stimuli on cytosolic $\mathrm{pH}$ in cultured insulinoma (HIT T15) cells. Biochem. Biophys. ACTA 1012:166-170

Mears, D., Sheppard Jr., N.F., Rojas, E., Atwater, I., Bertram, R., Sherman, A. 1996. A role for calcium release-activated current in pancreatic $\beta$-cell biphasic electrical activity. Biophys. J. 70:A362

Meissner, H.P., Atwater, I. 1976. The kinetics of electrical activity of B-cells in response to 'square wave' stimulation with glucose or glibenclamide. Horm. and Met. Res. 8:11-15

Meissner, H.P., Schmeltz, H. 1974. Membrane potential of beta-cells in pancreatic islets. Pfluegers Arch. 351:195-206

Meissner, H.P., Schmidt, H. 1976. The electrical activity of pancreatic $\beta$-cells of diabetic mice. FEBS Lett. 67:371-374

Misler, S., Gillis, K., Tabacharani, J. 1989. Modulation of gating of a metabolically regulated, ATP-dependent $\mathrm{K}^{+}$channel by intracellular $\mathrm{pH}$ in $\mathrm{B}$ cells of the pancreatic islet. J. Membrane Biol. 109:135-143

Nadal, A., Valdeolmillos, M., Soria, B. 1994. Metabolic regulation of intracellular calcium concentration in mouse pancreatic islets of Langerhans. Am. J. Physiol. 267:E769-E774

Pace, C.S., Tarvin, J.T., Smith, J.S. 1983. Stimulus-secretion coupling in $\beta$-cells: modulation by $\mathrm{pH}$. Am. J. Physiol. 244:E3-E18

Porte Jr., D., Pupo, A.A. 1969. Insulin response to glucose: Evidence for a two pool system in man. J. Clinical Invest. 48:2309-2319

Putney, J.W., Bird, G.S.J. 1993. The inositol phosphate-calcium signaling system in nonexcitable cells. Endocrine Rev. 14:610-631

Roe, M.W., Lancaster, M.E., Mertz, R.J., Worley III, J.F., Dukes, I.D. 1993. Voltage-dependent intracellular calcium release from mouse islets stimulated by glucose. J. Biol. Chem. 268:9953-995

Roe, M.W., Mertz, R.J., Lancaster, M.E., Worley III, J.F., Dukes, I.D. 1994a. Thapsigargin inhibits the glucose-induced decrease of intracellular $\mathrm{Ca}^{2+}$ in mouse islets of Langerhans. Am. J. Physiol. 266:E852-E862

Roe, M.W., Philipson, L.H., Frangakis, C.J., Kuznetsov, A., Mertz, R.J., Lancaster, M.E., Spencer, B., Worley III, J.F., Dukes, I.D. 1994b. Defective glucose-dependent endoplasmic reticulum $\mathrm{Ca}^{2+}$ sequestration in diabetic mouse islets of Langerhans. J. Biol. Chem. 269: 18279-18282

Rojas, E., Carroll, P.B., Ricordi, C., Boschero, A.C., Stojilkovic, S.S., Atwater, I. 1994. Control of cytosolic free calcium in cultured human pancreatic $\beta$-cells occurs by external calcium-dependent and independent mechanisms. Endocrinology 134:1771-1781

Rojas, E., Hidalgo, J., Carroll, P.B., Atwater, I. 1990. A new class of calcium channels activated by glucose in human pancreatic $\beta$-cells. FEBS Lett. 261:265-270

Rosario, L.M., Barbosa, R.M. Antunes, C.M., Silva, A.M., Abrunhosa, A.J., Santos, R.M. 1993. Bursting electrical activity in pancreatic $\beta$-cells-evidence that the channel underlying the burst is sensitive to $\mathrm{Ca}^{2+}$ influx through L-type $\mathrm{Ca}^{2+}$ channels. Pfluegers Arch. 424:439-447

Salgado, A., Silva, A.M., Santos, R.M., Rosario, L.M. 1996. Multipha- 
sic action of glucose and $\alpha$-ketoisocaproic acid on the cytosolic $\mathrm{pH}$ of pancreatic $\beta$-cells. Evidence for an acidification pathway linked to the stimulation of calcium influx. J. Biol. Chem. 271:8738-8746

Sánchez-Andrés, J.V., Soria, B. 1991. Muscarinic inhibition of pancreatic $\beta$-cells. Euro. J. Pharmacol. 205:89-91

Santos, R.M., Barbosa, R.M., Silva, A.M., Antunes, C.M., Rosario, L.M. 1992. High external $\mathrm{Ca}^{2+}$ levels trigger membrane potential oscillations in mouse pancreatic $\beta$-cells during blockade of K(ATP) channels. Biochem. Biophys. Res. Comm. 187:872-879

Santos, R.M., Rosario, L.M., Nadal, A., Garcia-Sancho, J., Soria, B., Valdeolmillos, M. 1991. Widespread synchronous $\left[\mathrm{Ca}^{2+}\right]_{i}$ oscillations due to bursting electrical activity in single pancreatic islets. Pfluegers Arch. 418:417-422

Scott, A.M., Atwater, I., Rojas, E. 1981. A method for the simultaneous measurement of insulin release and B cell membrane potential in single mouse islets of Langerhans. Diabetologia 21:470-475

Sturgess, N.C., Ashford, M.L.J., Cook, D.L., Hales, C.N. 1985. The sulphonylurea receptor may be an ATP-sensitive potassium channel. Lancet 8453:474-475

Taguchi, N., Aizawa, T., Sato, Y., Ishihara, F., Hashizume, K. 1995. Mechanism of glucose-induced biphasic insulin release: physiological role of adenosine triphosphate-sensitive $\mathrm{K}^{+}$channelindependent glucose action. Endocrinology 136:3942-3948

Thastrup, O., Dawson, A.P., Scharff, O., Foder, B., Cullen, P.J., Drøbak, B.K., Bjerrum, P.J., Christensen, S.B., Hanley, M.R. 1989. Thapsigargin, a novel molecular probe for studying intracellular calcium release and storage. Agents Actions 27:17-23

Tse, F.W., Tse, A., Hille, B. 1994. Cyclic $\mathrm{Ca}^{2+}$ changes in intracellular stores of gonadotropes during gonadotropin-releasing hormonestimulated $\mathrm{Ca}^{2+}$ oscillations. Proc. Natl. Acad. Sci. USA 91:97509754

Ward, W.K., Beard, J.C., Halter, J.B., Pfeifer, M.A., Porte, J., D.A. 1984. Pathophysiology of insulin secretion in non-insulindependent diabetes mellitus. Diabetes Care 7:491-502

Worley III, J.F., McIntyre, B., Spencer, B., Mertz, R.J., Roe, M.W., Dukes, I.D. 1994a. Endoplasmic reticulum calcium store regulates membrane potential in mouse islet $\beta$-cells. J. Biol. Chem. 269:14359-14362
Worley III, J.F., McIntyre, M.S., Spencer, B., Dukes, I.D. $1994 b$. Depletion of intracellular $\mathrm{Ca}^{2+}$ stores activates a maitotoxinsensitive nonselective cationic current in $\beta$-cells. J. Biol. Chem. 269:32055-32058

\section{Appendix}

The principle difference between the version of the model used in this paper and that employed in Bertram et al. (1995) is the choice of parameter values associated with the ER compartment. Recent data indicates that the concentration of free calcium in the ER is significantly greater than that computed with the earlier version of the model (Hofer \& Machen, 1993; Tse, Tse \& Hille, 1994). We have therefore decreased the leak permeability of the ER, which has the desired effect of raising $\mathrm{Ca}_{\mathrm{er}}$. The $I_{\mathrm{CRAN}}$ activation function has also been modified so that the half-activation level is now $40 \mu \mathrm{M}$ rather than $3 \mu \mathrm{M}$. Other changes in the model include a reduction in the effective volume of the ER (reflected in a smaller value of $\sigma$ ), and the replacement of a linear plasma membrane pump with a nonlinear term.

Steady-state activation/inactivation functions have the form $z_{\infty}=$ $1 /(1+\exp [(v z-V) / s z]): v m f=-20, s m f=7.5, v m s=-16, s m s=$ $10, v j=-53, s j=-2, v n=-15, s n=6(\mathrm{mV})$. The $I_{\mathrm{CRAN}}$ activation function is $r_{\infty}=1 /\left(1+\exp \left[\left(\mathrm{Ca}_{\mathrm{er}}-40\right) / 3\right]\right)$, such that the current activates when $\mathrm{Ca}_{\mathrm{er}}$ is low, with a half-saturation level of $40 \mu \mathrm{M}$. Time constants for activation of $I_{\mathrm{Kdr}}$ and inactivation of $I_{\mathrm{Cas}}$ are $\tau_{n}=4.86 /(1$ $+\exp [(V+15) / 6])$ and $\tau_{j}=\left(5 \times 10^{4} / \exp [(V+53) / 4]+(\exp [-(V+\right.$ 53)/4]) $+1.5 \times 10^{3}$ (msec).

The fraction of open $\mathrm{IP}_{3}$-activated $\mathrm{Ca}^{2+}$ channels is $\mathrm{O}_{\infty}=$ $\mathrm{a}_{\infty}^{3} \mathrm{~b}_{\infty}^{3} \mathrm{~h}_{\infty}^{3}$, correcting an error in the expression given in Bertram et al. (1995). The steady-state activation/inactivation functions for this channel are $a_{\infty}=\mathrm{Ca}_{i} /\left(\mathrm{Ca}_{i}+0.35\right), b_{\infty}=I P_{3} /\left(I P_{3}+0.2\right)$, and $h_{\infty}=$ $0.4 /\left(\mathrm{Ca}_{i}+0.4\right)$. In the absence of a muscarinic agonist, $I P_{3}=0$, so $\mathrm{O}_{\infty}$ $=0$.

SERCA pump flux is expressed as a Hill function, $J_{\mathrm{er}, \mathrm{p}} / P_{\mathrm{ip} 3}=$ $v_{\text {er,p }} \mathrm{Ca}_{i}^{2} /\left(\mathrm{Ca}_{i}^{2}+\mathrm{k}_{\text {er,p }}^{2}\right)$.

The values of parameters used in the model are given in the Table. The equations and parameters can also be obtained on the World Wide Web at: http://mrb.niddk.nih.gov/sherman

Table. Parameter values of the mathematical model

\begin{tabular}{llll}
\hline Parameter & Value & Parameter & Value \\
\hline$\overline{\mathrm{g}}_{\mathrm{Cas}}$ & $510 \mathrm{pS}$ & $\overline{\mathrm{g}}_{\mathrm{Caf}}$ & $810 \mathrm{pS}$ \\
$\overline{\mathrm{g}}_{\mathrm{K}(\mathrm{ATP})}$ & $150 \mathrm{pS}$ & $\overline{\mathrm{g}}_{\mathrm{Kdr}}$ & $3900 \mathrm{pS}$ \\
$\overline{\mathrm{g}}_{\mathrm{K}(\mathrm{Ca})}$ & $1200 \mathrm{pS}$ & $\overline{\mathrm{g}}_{\mathrm{CRAN}}$ & $75 \mathrm{pS}$ \\
$\mathrm{V}_{\mathrm{Ca}}$ & $100 \mathrm{mV}$ & $V_{\mathrm{K}}$ & $-70 \mathrm{mV}$ \\
$\mathrm{V}_{\mathrm{CRAN}}$ & $0 \mathrm{mV}$ & $\mathrm{Cm}$ & $6158 \mathrm{fF}$ \\
$\mathrm{V}_{\text {mem,p }} / \mathrm{V}_{\mathrm{i}, \mathrm{eff}}$ & $8 \times 10^{-4} \mu \mathrm{M} \mathrm{msec}^{-1}$ & $\mathrm{k}_{\mathrm{mem}, \mathrm{p}}$ & $0.35 \mu \mathrm{M}$ \\
$\mathrm{V}_{\text {er,p }}$ & $0.24 \mu \mathrm{M}$ & $\mathrm{k}_{\text {er,p }}$ & $0.09 \mu \mathrm{M}$ \\
$\alpha / \mathrm{V}_{\mathrm{i}, \text { eff }}$ & $3.6 \times 10^{-8} \mathrm{fA}^{-1} \mu \mathrm{M} \mathrm{msec} \mathrm{ms}^{-1}$ & $V_{\mathrm{i}, \text { eff }}$ & $7.19 \times 10^{6} \mu \mathrm{M}^{3}$ \\
$\mathrm{P}_{\text {leak }} / \mathrm{P}_{\mathrm{ip3}}$ & $3 \times 10^{-3}$ & $\sigma$ & 1 \\
$\lambda$ & $250 \mathrm{msec}$ & $\mathrm{IP}_{3}$ & $0 \mu \mathrm{M}$ \\
\hline
\end{tabular}

